\title{
LA INMIGRACIÓN EXTRANJERA A FERROL DURANTE EL S. XVIII
}

\author{
Por \\ ALFREDO MARTÍN GARCÍA
}

\section{RESUMEN}

La villa de Ferrol experimentó, en la segunda mitad del siglo XVIII, un importante crecimiento demográfico, merced a la erección en su puerto de los nuevos arsenales de la Corona. Las expectativas abiertas por esta novedosa situación, provocaron la llegada de un importante número de extranjeros, destacando la aportación británica, francesa, italiana y portuguesa. De entre ellos, los británicos adquirieron un notable papel en el organigrama de los arsenales y los franceses, ocuparon una posición privilegiada en el comercio de la villa.

\section{PALABRAS CLAVES}

Ferrol, inmigración extranjera, siglo XVIII, arsenales, comercio.

\section{ABSTRACT}

The town of Ferrol experienced an important demographic increase during the second half of $18^{\text {th }}$ century, thanks to the erection of the new crown arsenals in its port. The prospects opened up by this new situation, 
lead to the arrival of an important number of foreigners, highlighting the British, French, Italian and Portuguese contribution. The British attained an important role in the organization of the arsenals and the French held a privileged position in the town's commerce.

\section{KEYWORDS}

Ferrol, foreign inmigration, $18^{\text {th }}$ century, arsenals, commerce.

\section{EL PESO DE LA COLECTIVIDAD EXTRANJERA EN EL PRO- CESO MIGRATORIO FERROLANO ${ }^{1}$}

La conversión de la villa de Ferrol e mediados del siglo XVIII en un centro urbano de entidad en el contexto gallego, vino de la mano de la construcción en su rada de las imponentes instalaciones bélico-industriales auspiciadas por la Corona en el marco de su política de reactivación naval. A partir de ese momento, la localidad gallega será el punto de llegada de un denso flujo migratorio que la alimentará constantemente hasta finales de la centuria, momento en el que la crisis de la monarquía derivará en un importante recorte de las inversiones públicas en la capital departamental y, por ende, en el comienzo de una larga crisis de la que no saldrá prácticamente hasta mediados del siglo XIX. El proceso migratorio hacia Ferrol procede mayoritariamente del propio reino de Galicia y más concretamente de las feligresías rurales más próximas al nuevo enclave, si bien el aporte de la Galicia urbana es también porcentualmente destacable ${ }^{2}$.

${ }^{1}$ Abreviaturas empleadas: A.G.S. Archivo General de Simancas; A.G.M. Archivo General de Marina de Viso del Marqués (Ciudad Real); A.H.N. Archivo Histórico Nacional; A.M.F. Archivo Municipal de Ferrol; B.M.N. Biblioteca del Museo Naval de Madrid.

${ }^{2}$ Ver MARTÍNEZ, E., BURGO, M.C. y GONZÁLEZ, D.L. «Inmigración urbana en la Galicia del Antiguo Régimen: Santiago, Tuy y Ferrol a finales del siglo XVIII», pp. 389-402, en EIRAS, A., y REY, O., (Eds.), I Conferencia Europea de la Comisión Internacional de Demografia Histórica, Santiago 1993; MARTÍN, A., «Inmigración y estructura profesional en el Ferrol de finales del Antiguo Régimen», pp. 193-218, en Obradorio de Historia Moderna, n 6, Santiago 1997. 
Como ya se ha demostrado en trabajos anteriores, el peso de la colectividad extranjera en el contexto general de las procedencias del proceso migratorio ferrolano no va a ser nunca comparable, ni con el de la gallega, que es el auténtico dominador, ni tampoco con el del resto de regiones españolas ${ }^{3}$, pero su importancia radica en la posición que algunos de los miembros de este grupo conseguirán en la sociedad de acogida, así como en el monopolio que llevarán adelante en algunas profesiones. Esa escasez numérica de la colonia extranjera en Ferrol queda fielmente reflejada en los padrones de extranjeros custodiados en el Archivo Municipal de Ferrol ${ }^{4}$. Mandados elaborar al concejo ferrolano por el Consejo de Guerra con el fin de tener perfectamente controlados a los extranjeros residentes en una plaza de la importancia estratégica de la gallega, así como para presionar su conversión en súbditos de la Corona Católica, se convertirán en una interesante fuente para el conocimiento de esa minoría de hombres que jugó un papel destacado tanto en el esquema socio-laboral de las instalaciones bélico-industriales gallegas, como en otras actividades económicas más o menos ajenas al mundo castrense.

Desde el primer padrón, que data de 1765, al último, fechado en 1792, hay un número considerable de recuentos, algunos de ellos exhaustivos y repletos de datos -como el de $1791^{5}$ - y otros muy poco fiables -como los de 1766, 1781 o $1792^{6}$-, que a pesar de sus deficiencias nos servirán para marcar la evolución de la procedencia extranjera en la real villa y el peso de las diferentes colectividades. Los datos obtenidos de los recuentos a nuestro juicio más fiables son los siguientes:

\footnotetext{
${ }^{3}$ MARTÍN, A., Opus cit., p. 200.

${ }^{4}$ A.M.F., Padrones de extranjeros, Carp. 1016. Agradecemos públicamente al profesor Baudilio Barreiro la deferencia que ha tenido hacia nosotros al darnos a conocer esta fuente y, sobre todo, la infinita generosidad demostrada al cedernos su vaciado cuando él ya había comenzado con esa labor.

${ }^{5}$ El padrón de 1791 ofrece sistemáticamente no sólo el lugar de naturaleza de cada extranjero, sino también su edad, profesión, tiempo de residencia en la villa, estado civil -indicando incluso, en el caso de estar casado, si lo está con una española o una extranjera-, e incluso se puede hacer un análisis del nivel de firmas de la colonia extranjera.

${ }^{6}$ El recuento de 1766 es mandado repetir por el capitán general de Galicia por sus manifiestas incoherencias con respecto al del año anterior. A pesar de ello, el recuento saliente de ese retoque estadístico ofrece datos muy poco fiables con respecto a los padrones anteriores y posteriores. Algo similar acontece con los de 1785 y 1792.
} 


\begin{tabular}{lrrrrrrrrrrrr}
\hline & \multicolumn{1}{c}{$\mathbf{1 7 6 5}$} & \multicolumn{2}{c}{$\mathbf{1 7 6 7}$} & \multicolumn{2}{c}{$\mathbf{1 7 6 8}$} & \multicolumn{2}{c}{$\mathbf{1 7 6 9}$} & \multicolumn{2}{c}{$\mathbf{1 7 7 8}$} & \multicolumn{2}{c}{$\mathbf{1 7 9 1}$} \\
\hline Francia & 61 & $67^{\prime} 0$ & 70 & $71^{\prime} 4$ & 78 & $61^{\prime} 4$ & 94 & $67^{\prime} 2$ & 106 & $60^{\prime} 3$ & 96 & $50^{\prime} 3$ \\
Italia & 15 & $16^{\prime} 5$ & 11 & $11^{\prime} 2$ & 33 & $26^{\prime} 0$ & 31 & $22^{\prime} 1$ & 36 & $20^{\prime} 5$ & 48 & $25^{\prime} 1$ \\
G. Bretaña & 14 & $15^{\prime} 4$ & 16 & $16^{\prime} 3$ & 15 & $11^{\prime} 8$ & 13 & $9^{\prime} 3$ & 3 & $1^{\prime} 7$ & 3 & $1^{\prime} 6$ \\
Portugal & - & - & - & - & - & - & - & - & 17 & $9^{\prime} 7$ & 24 & $12^{\prime} 6$ \\
Alemania & 1 & $1^{\prime} 1$ & 1 & $1^{\prime} 1$ & 1 & $0^{\prime} 8$ & 2 & $1^{\prime} 4$ & 8 & $4^{\prime} 5$ & 6 & $3^{\prime} 1$ \\
Bohemia & - & - & - & - & - & - & - & - & 2 & $1^{\prime} 1$ & 6 & $3^{\prime} 1$ \\
P. Bajos & - & - & - & - & - & - & - & - & 2 & $1^{\prime} 1$ & 3 & $1^{\prime} 6$ \\
Malta & - & - & - & - & - & - & - & - & 2 & $1^{\prime} 1$ & 3 & $1^{\prime} 6$ \\
Suiza & - & - & - & - & - & - & - & - & - & - & 1 & $0^{\prime} 5$ \\
Hungría & - & - & - & - & - & - & - & - & - & - & 1 & $0^{\prime} 5$ \\
TOTAL & $\mathbf{9 1}$ & $\mathbf{1 0 0}$ & $\mathbf{9 8}$ & $\mathbf{1 0 0}$ & $\mathbf{1 2 7}$ & $\mathbf{1 0 0}$ & $\mathbf{1 4 0}$ & $\mathbf{1 0 0}$ & $\mathbf{1 7 6}$ & $\mathbf{1 0 0}$ & $\mathbf{1 9 1}$ & $\mathbf{1 0 0}$ \\
\hline
\end{tabular}

Los padrones nos hablan en primer lugar de la importancia secundaria del elemento extranjero en el contexto general ferrolano. Por poner dos claros ejemplos: el recuento de vecinos de la villa de Ferrol del año $1767^{7}$ arroja un total de 950 , ese mismo año el de extranjeros nos localiza a 98 integrantes de esa colectividad residiendo en Ferrol. En 1791, el padrón de extranjeros señala un número de 191 individuos, seis años más tarde el padrón de la villa habla de 4.100 vecinos $^{8}$. Parece pues evidente que numéricamente el grupo de los extranjeros presenta unas dimensiones reducidas, máxime si pensamos que no todos los señalados en sus respectivos padrones eran vecinos de la población. Asimismo, parece observarse un paulatino crecimiento de la colectividad extranjera en Ferrol durante la segunda mitad del siglo XVIII, pasándose de 91 integrantes en 1765 a exactamente cien más en 1791. Pero, aún a pesar de ese considerable aumento de efectivos, las cifras globales nos siguen hablando de un sector minoritario en el conjunto general de la población ferrolana.

En cuanto a las procedencias de este grupo de inmigrantes, la colonia francesa se presenta como la auténtica dominadora del proceso a lo largo de todo el período, suponiendo su número siempre más de la mitad del conjunto de extranjeros residentes en Ferrol. Sin embargo, esa preponderancia gala parece que va remitiendo a medida que nos acercamos al final de la centuria, produciéndose en la década de los noventa una reducción tanto numérica como porcentual de su presencia. Las causas pueden estar

${ }^{7}$ A.H.N., Consejos, Leg. 1.215 .

${ }^{8}$ A.M.F., Padrón a calle hita de 1797, Carp. 3.293-B. 
por un lado en el comienzo de la crisis socioeconómica de la localidad que motiva la marcha de aquellos inmigrantes que ya no ven tan interesantes los márgenes de beneficio que obtienen en ella, pero sobre todo habría que achacarla a las difíciles relaciones que viven la Corona española y la Francia revolucionaria por aquellas fechas.

La segunda colectividad en importancia es la italiana que, al contrario que la francesa, obtiene sus mejores cifras en el último recuento del XVIII, pasando de 15 integrantes en 1765 a 48 en 1791. Por su parte la colonia británica deja entrever un paulatino retroceso de su presencia a medida que nos acercamos a los últimos años del siglo XVIII, pasando de un $15^{\prime} 4 \%$ del total de procedencias foráneas al exiguo $1{ }^{\prime} 6 \%$ de 1791 . Es evidente que ambos elementos derivan de las especiales condiciones del movimiento migratorio británico, que aparece de repente a finales de la década de los cuarenta, tras las gestiones de los agentes de la Corona Católica en Gran Bretaña, y que no se realimentará con nuevas adquisiciones humanas tras la caída en desgracia del método inglés de construcción naval frente al francés, que se convertirá en el preferido por el gobierno borbónico desde la década de los sesenta. En lo que respecta al resto de colectividades extranjeras su presencia es meramente testimonial; tan sólo llama la atención la repentina aparición en el último tercio de siglo de inmigrantes portugueses que hasta aquel momento no habían sido mencionados por los padrones.

\section{LA INMIGRACIÓN BRITÁNICA ${ }^{9}$}

Si bien es cierto que -como acabamos de observar en los padrones de extranjeros del concejo ferrolano- la colectividad británica no es, ni mucho menos, la de mayor importancia numérica, su singularidad le hace ocupar la primera parte de nuestro estudio, por ser el suyo un proceso migratorio bajo contrata auspiciado por la Corona ${ }^{10}$. Las relaciones entre

\footnotetext{
${ }^{9}$ La documentación de Simancas incluye a los súbditos de Gran Bretaña con el genérico nombre de «ingleses», incluyendo en el término a los trabajadores irlandeses.

${ }^{10}$ Podríamos citar un importante número de casos de ese tipo ocurridos tanto en tiempos de los Austrias como de los propios Borbones. Por ejemplo, conocida es por todos la presencia en tiempos de Felipe II de expertos en variadas materias procedentes de los territorios no peninsulares de la monarquía (ingenieros militares italianos, jardine-
} 
las Islas Británicas y Ferrol, desde la creación de las instalaciones navales en el siglo XVIII hasta comienzos del siglo XX, han sido de gran importancia, quizás no desde el punto de vista cuantitativo pero desde luego sí desde el cualitativo. La ubicación en la rada gallega de los principales astilleros de la Península y el status de Gran Bretaña como la nación puntera desde el punto de vista tecnológico en el campo de la construcción naval, hicieron que no fueran pocos los técnicos ingleses que recalaron en las instalaciones ferrolanas para desplegar sus conocimientos a lo largo de los siglos XVIII, XIX y XX, en aquellos momentos de especial dinamismo en la actividad constructiva de los astilleros gallegos. El inicio de esta fecunda relación comenzó prácticamente con la creación en Esteiro de los importantes astilleros que servían como punta de lanza a la ambiciosa política de reconstrucción naval ideada por el marqués de la Ensenada. De hecho, se podría decir que antes de estar finalizadas las obras de acondicionamiento del monte Esteiro se habían comenzado ya los contactos en Gran Bretaña para atraer a las nuevas instalaciones a un selecto grupo de especialistas en el campo de la construcción naval que vendrían a desarrollar sus actividades a los astilleros reales $^{11}$. Acompañados, en la mayoría de los casos, por sus propias fami-

ros flamencos, etc.). De la misma manera, hubo en el reinado de Felipe IV notables intentos por potenciar las manufacturas castellanas con la contratación de técnicos extranjeros, flamencos fundamentalmente, labor continuada en el reinado de Carlos II por la Junta de Comercio que atrajo hacia la península un destacado contingente de especialistas foráneos, fundamentalmente también flamencos, en diversos campos de las manufacturas -lana, vidrio, seda...-. La Casa de Borbón continuó con esa ya secular costumbre de conseguir una rápida modernización tecnológica de su industria a través de la importación de técnicos y maquinaria extranjera, actuando sus embajadas en los países más desarrollados como auténticos centros de espionaje industrial; Ver ELLIOT, J.H., $E l$ conde-duque de Olivares, Barcelona 1998, p.; KAMEN, H., La España de Carlos II, Barcelona 1987, p. 129; Lynch, J., El siglo XVIII, Barcelona 1991, p. 193.

${ }^{11} \mathrm{Si}$ bien antes de la creación del astillero de Esteiro ya se habían construido en las gradas de A Graña un pequeño número de embarcaciones, lo cierto es que el despegue de Ferrol como principal centro de la construcción naval española no se producirá hasta la erección de esas nuevas instalaciones. El profesor Vigo Trasancos ha demostrado en su momento que las obras del enclave se desarrollaron entre 1749 y 1753 , por lo que es evidente que las contrataciones de los expertos británicos se produjeron cuando éstas estaban en sus comienzos. Ver VIGO, A., Arquitectura y urbanismo en el Ferrol del siglo XVIII, Vigo 1985, p. 177. 
lias y con un contrato de por medio - que les garantizaba una envidiable posición económica e incluso jerárquica dentro de la pirámide laboral del departamento- los ingleses desarrollaron un papel destacado en la dinámica actividad de las instalaciones ferrolanas en la década de los cincuenta, para pasar luego a un segundo plano tras el cambio de preferencias por parte del gobierno español del sistema inglés, personificado en el todopoderoso constructor Rooth, al francés, liderado por el no menos influyente Gautier. Precisamente, Ricardo Rooth un inglés católico de origen irlandés será el emblema de las contrataciones borbónicas en la Gran Bretaña.

La incontestable hegemonía británica en los mares durante el siglo XVIII derivó en la corte de Fernando VI en un acentuado prestigio de todo lo inglés a lo que, por supuesto, no quedó indiferente el propio marqués de la Ensenada, visiblemente interesado en hallar el secreto del éxito de la potencia rival. Así, el gobierno borbónico decidió llevar adelante una política de atracción hacia España de miembros altamente cualificados en el campo de la construcción naval, en donde se creía radicaba precisamente la base del poderío marítimo inglés ${ }^{12}$. Para lograr un objetivo tan difícil y delicado -se requería la absoluta ignorancia del gobierno británico- se preparó sigilosamente un viaje de un agente de la Corona a la cuenca del Támesis para tantear el terreno y tentar a aquellos individuos que fueran más apetecibles por sus habilidades para llevar adelante el ambicioso proyecto de reconstrucción naval ideado por el ministro. Ensenada designó para la misión a un hombre de toda su confianza, el marino y experto en materia de construcción naval, Jorge Juan. Su estancia en Inglaterra, de riguroso incógnito ${ }^{13}$, duró aproximadamente un año, período en el que consiguió cierta amistad con constructores de la zona londinense, aunque pronto se percató de que las posibilidades de lograr atraer a España a los más diestros eran harto discretas, por lo que habría que conformarse con hombres de valía menos contrastada. Efectivamente, cuando en la Pascua de 1749 el espía español entre en contacto en Londres con dos constructores ingleses, Mr. Bith ("sin contradicción el mejor que tiene la Inglaterra») y Mr. Rooth ("muy buen cathólico sin embargo de

\footnotetext{
${ }^{12}$ MERINO, J.P., La armada española en el siglo XVIII, Madrid 1981, p. 49

${ }^{13}$ Durante su periplo británico se hizo llamar M. Jogues.
} 
ser hijo de esta ciudad») ${ }^{14}$, desechará por completo la posibilidad de contratar al primero de ellos, el hombre ideal para los planes de Ensenada, ante la holgada situación económica que disfrutaba ya en su tierra:

«a Mr. Birth no lo podemos conseguir, siendo hombre de muchos millares de libras esterlinas de caudal, hallándose con varios diques propios y fabricando muchos navios de su cuenta» ${ }^{15}$.

Será pues el segundo el objetivo prioritario del marino español, seguramente más que por su pericia, por la imposibilidad de encontrar a otro que decidiese marcharse de su patria, aún a pesar de las excelentes condiciones económicas ofertadas y de los engaños con los que el marino intentaba atraerlos, como el de actuar de agente para las colonias inglesas en América ${ }^{16}$. Los resultados cosechados en las negociaciones de Jorge Juan dejaban a Rooth como la única salida posible:

«... la qual tengo por cierto es la sola (persona) que puede sacarle de su patria: pues haviendo solicitado otros maestros, tanto de su profesión como de fábrica de jarcia con el disfraz de que les pedían de la Nueva Inglaterra, con partidos aún más ventajosos que los que he hecho a Rooth, todos reusan el abandonar su patria: de tal suerte que por lo presente aún no veo apariencia de poder prometer a V.E. otros maestros constructores que lleguen a la habilidad de Rooth, no obstante no pierdo las esperanzas, pues algunos días más nos pueden ofrecer algo» ${ }^{17}$.

${ }^{14}$ A.G.S., Secretaría de Marina, Leg. 233, Carta de Jorge Juan a Ensenada, (Londres, 9 de abril de 1749).

${ }^{15}$ A.G.S., Secretaría de Marina, Leg. 233, Carta de Jorge Juan a Ensenada, (Londres, 9 de abril de 1749).

${ }^{16}$ En junio de 1749 Jorge Juan informaba a Ensenada de la toma de contacto con otro maestro de construcción, D. Alexandro French, "que se hallaba algo disgustado» en su país, pero a pesar de los engaños con los que fue el marino español, proponiéndole una hipotética marcha a Nueva Inglaterra, el inglés rechazó tajantemente la oferta «sin embargo de haver bevido antes un poco». A.G.S., Secretaría de Marina, Leg. 233.

${ }^{17}$ A.G.S., Secretaría de Marina, Leg. 233, Carta de Jorge Juan a Ensenada, (Londres, 9 de abril de 1749).

«CUADERNOS DE ESTUDIOS GALLEGOS», Tomo XLVIII, Fascículo 114, Santiago 2001. 
Así pues, el constructor de origen irlandés se convertirá en la pieza fundamental de las contrataciones españolas en Gran Bretaña, una vez pasado el, al menos en apariencia, riguroso examen de sus habilidades que Jorge Juan le impuso a petición del propio Ensenada ${ }^{18}$. No se quería correr ningún riesgo, el ministro exigía que el hombre que se habría de encargar de la dirección de las obras en los astilleros de la Corona fuera un individuo no sólo con un importante bagaje teórico, sino también con experiencia contrastada en la construcción de bajeles; había que evitar errores en un punto tan crucial para el futuro de la Armada, errores que se habían cometido con demasiada frecuencia, según Ensenada, por parte de la administración española ${ }^{19}$ y que los propios portugueses habían sufrido recientemente, confiando en la palabra dada por un inglés sobre sus habilidades en el campo de la construcción naval y que terminó en la mayor de las decepciones cuando ya en Lisboa se comprobó que «no havia jamás construido ni la menor lancha ${ }^{20}$. Si Rooth demostraba ser el hombre que la Corona necesitaba, ésta no repararía en gastos para hacerse con sus servicios. Y a este respecto, las conclusiones de Jorge Juan no podían ser más favorables al constructor inglés; Rooth había convencido al marino español tanto en el campo teórico como en el práctico y se hacía merecedor de los favores de España:

«pues además de estar instruido de lo mejor que he visto en la fábrica de planos y theórica, saca los más hermosos navios del río, que los prácticos aseguran son de muy buenas propiedades en el mar. Esto practica 14 años ha: por ello se halla tan adelantado que tiene astillero y dique propio, y mucho en que trabajar, sin embargo de la mancha de ser cathólico que es tal en este país» ${ }^{21}$.

\footnotetext{
18 Jorge Juan una vez visto el interés mostrado por Rooth a su oferta le pidió la realización de un plano de un navío y otro de una fragata para conocer sus habilidades teóricas.

19 «porque la experiencia nos ha enseñado con no pequeño gasto y perjuicio del servicio que en vez de útiles, hemos admitido sobre su palabra extrangeros innútiles que nada han hecho de quanto avian ofrecido", A.G.M., Secretaria de Marina, Leg. 233, Carta de Ensenada a Jorge Juan, (Aranjuez, 24 de abril de 1749).

${ }^{20}$ A.G.S., Secretaría de Marina, Leg. 233, Carta de Jorge Juan a Ensenada, (Londres, 19 de mayo de 1749).

${ }^{21}$ AG.S., Secretaría de Marina, Leg. 233.
} 
La decisión estaba pues tomada: aún reconociendo la imposibilidad de sacar de Gran Bretaña a las cabezas más visibles de la construcción naval de aquel país, parecía que la contratación de Rooth iba a resultar de gran utilidad a la Corona, por lo que ésta accedió sin apenas oposición a las condiciones impuestas por el inglés, que exigía para desplazarse a España con su familia un sueldo de una libra esterlina diaria, más entre 50 y 60 para el viaje, además de la contratación -con un sueldo de unas cien libras anuales y algo para los gastos de desplazamiento- de sus oficiales de confianza junto a un carpintero de lo menudo «que es trabajo separado de el de constructor en este país y muy preciso que aprendan los nuestros, porque de él depende la hermosura del navio»"22. Las condiciones económicas, muy gravosas, no representaban ningún problema para una monarquía que con tanto empuje se había lanzando a la reconstrucción de la marina de guerra, y en cuanto a la contratación de ayudantes, más que un obstáculo era un punto a favor, dadas las imperiosas necesidades de mano de obra especializada para los arsenales de la Corona. Ni siquiera la condición de Rooth más cuestionable que consistía en «ser expótico en su departamento y que no ha de haver otro que le supedite $»^{23}$, es decir, en asumir el mando completo de los trabajos en los astilleros sin intromisiones de ningún tipo, fue cuestionada por Ensenada. La contratación del constructor de origen irlandés sería complementada con la adquisición de oficiales primeros de construcción, mucho más fáciles de conseguir que los maestros y según Jorge Juan tan hábiles como ellos.

Sin duda alguna, Ricardo Rooth era la pieza clave del entramado de contrataciones españolas en Gran Bretaña pero, por supuesto, no fue la única. Otro de los objetivos del marino español en Inglaterra era la localización de un buen maestro de lonas, lo que se consiguió mediante la contratación de Patricio Lahey, «irlandés católico, hombre de mucha razón y habilidad». Con ella se lograba a todas luces el deseo de Jorge Juan de conseguir precisamente los servicios de un irlandés, dada la fama que tenían los operarios de ese país en la confección de lonas. Las condiciones económicas eran también en este caso ciertamente intere-

${ }^{22}$ A.G.S., Secretaría de Marina, Leg. 233, Jorge Juan a Ensenada, (Londres, 9 de abril de 1749).

${ }^{23}$ A.G.S., Secretaria de Marina, Leg. 233. 
santes, acompañándole además en su periplo su mujer y dos operarios cualificados, además de varios telares y un número importante de instrumental. A partir de estos dos hombres y de sus operarios se irá configurando el programa de recluta de técnicos ingleses para los astilleros españoles ${ }^{24}$.

Para la marcha de todos ellos y sus familias a España se habían de tomar las máximas precauciones. No era recomendable ni agruparlos a todos en una misma embarcación, por las sospechas que ello podía generar ante las autoridades británicas, ni contratar los servicios de una embarcación inglesa, sobre todo tras el conocidísimo incidente del Metcafe ${ }^{25}$. Por ello se dispuso su salida a cuentagotas, así Rooth y los suyos no se marcharían de su hogar hasta concluir con la construcción del barco que estaban realizando; para tal fin, Jorge Juan había localizado una fragata vizcaína que los alojaría "a corta ventaja que se le de», llevándolos hasta Bilbao, desde donde el corregidor les daría transporte hasta Ferrol. Por su parte, los ayudantes y demás operarios serían embarcados en diferentes navíos, ya fuera con destino a Bilbao o incluso a Oporto, con el fin de disimular aún más si cabe el verdadero: la ciudad departamental. Aún a pesar de todas estas prevenciones, el propio Jorge Juan, junto con los últimos integrantes de las contrataciones españolas en Gran Bretaña estuvieron a punto de acabar con sus huesos en la cárcel cuando las autoridades británicas descubrieron las actividades de los agentes de la Corona española, lo que obligó al marino a hacerse pasar por marinero y embarcarse en un buque de Santoña con el que logró escapar a Boulogne junto con la última remesa de técnicos ${ }^{26}$.

\footnotetext{
${ }^{24}$ Merino Navarro localiza en los papeles de Simancas un total de 69 ingleses e irlandeses contratados por Jorge Juan para venir a España: 5 maestros de construcción, 6 contramaestres de construcción, 3 escultores, 7 maestros de armar y aparejar, 2 motoneros, 2 barreneros, 17 carpinteros de ribera, 12 carpinteros de blanco, 2 caldereros, 8 aserradores, 2 herreros, 2 intérpretes y 2 criadas irlandesas que vienen a Ferrol con Rooth. Un número al que habría que incrementar los familiares que sabemos se desplazaron con la mayoría de ellos. Ver MERINO, J.P., Opus cit., p. 102.

${ }^{25}$ Aquella tensa situación vivida motivó la renuncia por parte de Jorge Juan a volver a contratar un barco inglés, "porque bastará que uno de los marineros sea infiel a su capitán para que se haga declaración de ello», A.G.S., Secretaría de Marina, Leg. 233.

${ }^{26}$ MERINO, J.P., Opus cit., p. 50.
} 
Indudablemente, el principal aliciente para la marcha de estos técnicos a España era el económico, aunque no había duda que podía haber determinadas circunstancias que en algunos casos facilitaban esa marcha; por ejemplo, en el caso del propio Rooth encontramos motivaciones relacionadas con su credo religioso. De hecho, antes de conocer las verdaderas intenciones de Jorge Juan ya le había comentado «lo disgustado que estaba del trato que le dieron en la entrada del Pretendiente, y el gusto con que recibiría passar a otro reyno, como lo hiciessen algún partido acomodado $»^{27}$. De todas maneras, tales circunstancias no puede obviar lo evidente: los ingleses que llegan a Ferrol lo hacen principalmente por unas condiciones económicas muy beneficiosas y esa es la causa principal de este movimiento humano, sin ella dicho desplazamiento no se produciría. La gran mayoría de los ellos estipularon las condiciones de su venida con los agentes de la Corona de manera oral, a excepción de Eduardo Bryant, otro de los constructores contratados, y su compañero Guillermo Richards, maestro de lo menudo, que quizás temiendo algún tipo de engaño o simplemente para tener un aval en caso de problemas, redactaron de acuerdo con Jorge Juan una convención que, de hecho, ejemplifica de manera palpable las condiciones con las que viajaron todos ${ }^{28}$. El acuerdo, que comenzaba con la promesa de realizar su trabajo en el astillero en donde fuera asignado «según el mexor y más nuevo méthodo que se practica en Ynglaterra», se componía de nueve capítulos. En ellos se estipulaba el sueldo -en este caso 300 libras esterlinas mensuales ${ }^{29}$-, comprometiéndose además la Corona a proporcionar al contratado una casa en el mismo astillero «libre de todas imposiciones» para él y su familia, amén de los privilegios de criados y demás que gozaban los constructores en los astilleros británicos. Asimismo, las autoridades españolas se comprometían al pago de los gastos del viaje tanto de él como de su familia hasta su definitiva colocación en el astillero a determinar y a surtir a los suyos del dinero necesario para sobrevivir en Inglaterra hasta su partida a España, saliendo estos últimos fondos del propio sueldo de Bryant.

\footnotetext{
${ }^{27}$ A.G.S., Secretaría de Marina, Leg. 233.

${ }^{28}$ Cuando Jorge Juan envía a Ensenada la copia del contrato señala que «estas mismas combenciones son las que contraté con todos los demás, con sola la diferencia que éstos las han querido poner por escripto y los otros se contentaron con la palabra». A.G.S., Secretaria de Marina, Leg. 236.

${ }^{29}$ En el caso de Richards el sueldo era de 150 libras esterlinas al año.
} 
Sin duda un capítulo importante era el sexto, pues deja a las claras lo beneficioso del acuerdo para los técnicos ingleses que no sólo gozaban de un sueldo elevado sino que podían disfrutar de él de por vida ${ }^{30}$. De la misma manera, había otras cláusulas por las que el constructor inglés se aseguraba ciertos márgenes de libertad; por ejemplo el capítulo séptimo, remarcaba la imposibilidad de ser destinado a alguno de los dominios de la Corona Católica fuera de la Península «sin que preceda su libre consentimiento». En la misma línea estaría el octavo que les daba absoluta libertad para regresar a Inglaterra o a cualquiera de los dominios de su rey «sin que ninguno de los vasallos de S.M. Cathólica les ponga el menor impedimento en ello». Por último, el capítulo noveno preservaba la libertad de culto de los ingleses «sin ser por esto o qualquier otra cosa maltratado por ninguno de los vasallos de S.M. Cathólica ni estrangeros».

Ferrol fue el punto geográfico acordado por Jorge Juan y Ensenada para reunir a todos los trabajadores ${ }^{31}$, con el fin de, una vez llegado todos y superado su examen de habilidades, procederse a su repartición por todos los astilleros españoles. Rooth -el más cualificado de todos los maestros de construcción- se quedó en el Real de Esteiro mientras Eduardo Briant era destinado a Cartagena, Matheo Mullin a Cádiz, David Howel a Guarnizo y Almond Hill a la academia de guardia marinas. El hecho es que los mejores y más diestros especialistas contratados en Gran Bretaña se quedaron en las instalaciones gallegas. A partir de ese repartimiento de técnicos entre los astilleros peninsulares comenzará la verdadera labor de los ingleses en las instalaciones, gozando de una gran autonomía en sus actividades. Entre 1758 y 1760 trabajaban en las obras de Ferrol un total

\footnotetext{
${ }^{30}$ "Que el dicho Eduardo Bryant tendrá la livertad de gozar de dicho empleo de constructor y de su sueldo con todos los privilegios que le son anexos y gozan en el Reyno de España los constructores por toda su vida, o por todo el tiempo que el dicho Bryant gustase». A.G.S., Secretaria de Marina, Leg. 236.

${ }^{31} \mathrm{La}$ llegada de todos los ingleses a Ferrol y las dificultades de las autoridades gallegas para alojarlos convenientemente motivó su protesta, e incluso su desconfianza ante las promesas de la Corona, algarabía que aprovecharon algunos para intentar conseguir mayores prerrogativas, como en el caso de Rooth que exigió privilegios no convenidos con Jorge Juan. Ensenada, en carta fechada en Aranjuez el 19 de mayo de 1750, autorizará a Cosme Álvarez a "agasaxar a esa gente y si fuere menester gastar algún dinero en contentarla», pero subrayándole que en ningún caso aceptase más privilegios de los ya acordados con anterioridad. A.G.S., Secretaría de Marina, Leg. 236.
} 
de 15 ingleses, entre ellos el propio Rooth que recibía un 94 reales y 29 maravedíes desde el primero de septiembre de 1749 en el que ocupó el puesto de maestro constructor en el departamento ${ }^{32}$. La importancia jugada por Rooth en los planes navales de la Corona se manifestaron asimismo en su designación desde 1752, en el puesto de capitán de la maestranza, cobrando ambos sueldos a pesar de ir contra las ordenanzas, amén de gozar de otros privilegios como el de poseer cuatro criados para el servicio de su casa y huerta ${ }^{33}$. Además de Rooth trabajaba en el astillero otro maestro de construcción, David Howell, que había estado anteriormente sirviendo en Guarnizo y que no contaba con la confianza de las autoridades de marina ni por su pericia en la construcción de bajeles, ni por su forma de ser. Junto a ellos, había dos ayudantes de construcción-Guillermo Turner y Tomás Hewet-, y un contramaestre de construcción, Tomás Willians, que había venido de Guarnizo junto a Howell y del que el intendente Perea desconfiaba en sumo grado acusándolo de ser «caviloso con inquietud y disimulo y dictador de las inconsequencias del constructor Howell» ${ }^{34}$.

Tenemos también constancia documental del número y estado laboral de los británicos tres años más tarde cuando por vía reservada de Marina, Arriaga -Madrid, 22 de diciembre de 1762- pida a los intendentes de los tres departamentos peninsulares que le facilitasen un listado de trabajadores ingleses, haciendo distinción de los irlandeses, con un dictamen sobre su habilidad, así como del grado de confianza del que gozaban, atendiendo a las circunstancias bélicas del momento. El objetivo era despedir a aquellos no necesarios o de los que pudiera haber sospecha de escasa lealtad a la monarquía. En el caso de las instalaciones ferrolanas, la respuesta vendría firmada por el intendente Francisco Nuñez Ibáñez el 2 de enero de 1763, aunque, eso sí, movido por los remordimientos de

\footnotetext{
${ }^{32}$ Poseemos dos recuentos, uno del 12 de septiembre de 1758 y otro del 15 de enero de 1760, ambos firmados en Esteiro por el intendente Perea. A.G.S., Secretaría de Marina, Leg. 236.

${ }^{33}$ Por el puesto de capitán de la maestranza cobrará un total de 190 escudos mensuales, 80 de sueldo y 110 de gratificación. Según los cálculos del intendente Perea en 1758, Rooth ganaría la nada despreciable cantidad de 56.891 reales y 10 maravedíes de vellón al año. A.G.S., Secretaría de Marina, Leg. 236.

${ }^{34}$ A.G.S., Secretaria de Marina, Leg. 236.
} 
poder dañar a algún inglés inocente por sus sospechas, suplicaba al ministro que aquellos tachados por él de poco fiables no recibieran por ello ningún perjuicio más que el de retirarse, mientras se mantuviese el conflicto armado, del puerto ferrolano ${ }^{35}$. En ese momento se encontraban trabajando en el Real de Esteiro un total 21 trabajadores de aquella procedencia, 14 irlandeses y 7 ingleses. Del total de irlandeses aparece tan sólo uno del que el intendente desconfiaba, Jaime Pepper, carpintero de blanco, ya que, según palabras de Nuñez, era «saturnino y de corazón inglés $»^{36}$. Asimismo otro, D. Sebastián Creagh, que era médico no se desconfiaba de él a pesar de ser también de "corazón inglés» y se subrayaba la importancia de no perder sus servicios dada su habilidad. Había por otro lado cuatro de ellos cuya aportación a los trabajos en los astilleros no se consideraban necesaria.

Más difícil era la integración de los operarios ingleses; de los siete que disfrutaban de pagas del rey en Ferrol había dos, David Howell -constructor- y Tomás Willians -contramaestre de construcción- que mantenían sus creencias heréticas. Tales eran, por cierto, los dignos de mayor desconfianza por parte del intendente ferrolano. El primero porque aún mantenía a su familia en Inglaterra además de ser «digno de notar su empeño de no aprender una palabra española», y el segundo porque no sólo no había renegado de su fe, sino que persuadía a sus compatriotas para que no abjurasen. Asimismo, se citaba a Doña Juana Rooth, la viuda de Ricardo Rooth la cual, explicaba el intendente, sería conveniente mandarla a vivir a otro lugar "por que de ordinario hay yngleses en su casa» ${ }^{37}$. Por su parte, otros tres se habían catequizado en Ferrol y otro ya era católico antes de llegar a la sede de los arsenales.

La Corona, una vez analizado el informe de Nuñez, decidió despedir a ocho de esos operarios -entre ingleses e irlandeses-, un deseo que en la mayoría de los casos chocaba con los ventajosos contratos firmados con

\footnotetext{
${ }^{35}$ «... me es indispensable suplicar a V.E. que mi dictamen de ningún modo se encamina sino a que algunos de ellos por los corrillos que suelen formar para celebrar las cosas de su nación o otras señales que hayan dado, passen a otros departamentos sin que recivan perjuicio de esta Providencia que la miro precisa para la seguridad del puerto». A.G.S., Secretaría de Marina, Leg. 237.

${ }^{36}$ A.G.S., Secretaría de Marina, Leg. 237.

${ }^{37}$ A.G.S., Secretaría de Marina, Leg. 237.
} 
los susodichos y que imposibilitaban la acción de la Corona sin la anuencia de los propios afectados. Por ello las autoridades de marina iniciaron conversaciones con aquellos operarios no necesarios con el fin de llegar a un acuerdo monetario para rescindir el contrato. De esta manera, poco a poco, la presencia británica se irá diluyendo a lo largo de la segunda mitad del siglo XVIII, como confirman los padrones de extranjeros, de 16 en el de 1767 a tan sólo 3 en $1792^{38}$, no volviéndose a producir un fenómeno de estas características hasta la década de los cincuenta del siglo XIX en la que aparecen un número considerable de técnicos británicos trabajando en las instalaciones.

Así pues, la característica fundamental del proceso migratorio británico hacia Ferrol, vino dada por su íntima relación con los planes borbónicos de reconstrucción naval. Fue un proceso un tanto particular en el contexto general del movimiento migratorio hacia Ferrol durante el siglo XVIII y se inició por unas gestiones secretas de agentes de la Corona en la cuenca del Támesis que posibilitó un movimiento, en la mayoría de los casos familiar, y bajo unas condiciones económicas y laborales muy ventajosas. Cuando los gustos del gobierno se desviaron hacia el modo de construcción francés, los «ingleses» comenzaron a perder peso en el organigrama laboral de los astilleros de la Corona y ello motivó la paulatina desaparición de la colonia británica en Ferrol, bien porque tras negociaciones con ésta, alguno optaron por su regreso a las Islas Británicas, bien porque al no haber nuevas incorporaciones, los descendientes de británicos quedaron ya difuminados entre la masa de trabajadores nacionales.

Tan sólo hay un caso diametralmente opuesto a esta generalización realizada; se trata del vicecónsul británico en Ferrol, D. Luis Meagher O'Brien, un irlandés que vivirá junto con su familia en la capital de Departamento alrededor de treinta años. En este excepcional caso, la razón de la venida del inmigrante es también económica, pero muy alejada de los intereses del resto de sus compatriotas. Como él mismo explicará a la

${ }^{38}$ De los 16 de 1767, 15 dependían del erario público, mientras que en 1792 aparecen una irlandesa que ha jurado fidelidad al rey de España, Da Marcelina Ansel, y dos súbditos de su Graciosa Majestad que mantienen su fidelidad a la Corona británica: el también irlandés D. Luis Meages O'Brien -teniente cónsul de Gran Bretaña en Ferrol-y el inglés Tomás Willians, maestro fundidor en la Real Fábrica de cobre de Jubia. A.M.F., Padrones de extranjeros, Carp. 1016. 
Sala de Gobierno del Consejo de Castilla en septiembre de 1793, su decisión de instalarse en la década de los sesenta en la Real Villa vino dada porque pensaba que "este pueblo ofrecía por su comercio algunas ventajas que le proporcionasen en él su establecimiento a perpetuidad ${ }^{39}$. Era pues, O'Brien un comerciante ávido de enriquecerse con las posibilidades que ofrecía una nueva y populosa población necesitada de un sin fin de productos que no le podía ofrecer su pobre hinterland; y parece que sus negocios no le fueron del todo mal, al menos antes de que la localidad entrase en la aguda crisis finisecular que precipitaría una larga decadencia de casi medio siglo. En ese momento, el comerciante británico optará por marcharse a otra localidad con mayores expectativas de futuro ${ }^{40}$.

\section{LA INMIGRACIÓN FRANCESA}

Como ya señalamos anteriormente, la colectividad francesa es la más importante de todas las extranjeras afincadas en Ferrol durante la segunda mitad del siglo XVIII; su preeminencia en los padrones va desde el primero de 1765 hasta el último de 1792, y en todos ellos supera el 50\% del total de la colonia extranjera en la capital departamental, observándose, eso sí, a medida que nos acercamos al final del siglo, una paulatina pérdida porcentual con respecto al resto de colectividades. Al contrario de lo sucedido con los británicos, en los que es relativamente fácil estudiar los orígenes, las motivaciones e incluso los grados de permeabilidad de los recién llegados con respecto a la sociedad receptora, el francés es un movimiento mucho menos homogéneo y, sin lugar a dudas, de una excepcionalidad menor. Cierto es que también podemos encontrar en Ferrol franceses que vienen a trabajar a las instalaciones navales en calidad de técnicos especializados, como es el caso del todopoderoso constructor

${ }^{39}$ A.H.N., Consejos, Leg. 1546, Exp. 27.

${ }^{40}$ D. Luis Meagher O'Brien pedirá desde Ferrol el 18 de septiembre de 1793 al Consejo de Castilla que le permitan realizar la rifa de una espaciosa casa con sus almacenes y huerta situada en la calle de Dolores y tasada en 246.030 reales de vellón, para pagar a sus acreedores y saldar sus cuentas en Ferrol antes de partir a su nuevo destino en Santander, ya que si no, se vería obligado a venderla a un valor mucho menor del real. El Consejo responderá el 28 de noviembre con la denegación de tal propuesta. A.H.N., Consejos, Leg. 1.546, Exp. 27. 
Gautier, que llegará a la capital departamental en junio de 1769 con unas atribuciones similares o incluso superiores a las de Rooth, o el ingeniero militar José Petit de la Croix, personaje que gozará de una singular importancia durante la década de los cincuenta en el trazado de la nueva ciudad $^{41}$. Asimismo, no parece descabellado calificar de migración por contrata la realizada desde la provincia de Bearne por parte de un pequeño grupo de herreros que acabarán residiendo en la capital departamental tras un breve impas en Guarnizo. De todas maneras, en el caso francés no estamos ante una política tan definida como la que la Corona había desarrollado con los británicos, siendo esos ejemplos más una excepción que una regla genérica aplicable al conjunto de la colectividad gala.

Atendiendo a los datos que nos ofrecen los diferentes padrones de extranjeros del concejo ferrolano, podríamos dividir a la colonia francesa en tres grupos; por un lado los grandes comerciantes que se instalan en Ferrol con el objetivo de aprovecharse de las innegables ventajas que ofrecía la localidad como ciudad de nuevo cuño, nacida prácticamente de la nada y con unas ingentes necesidades de toda clase de productos ante la pobreza de su comarca circundante. En este grupo estarían englobados hombres de la importancia en el contexto socioeconómico departamental de Santiago Beaujardin o de Juan Lestache. Por otro lado, nos encontramos con un destacado número de hombres que desempeñan su labor en las instalaciones militares, mayoritariamente como miembros de la maestranza. Finalmente, existe también un sector de inmigrantes galos desarrollando actividades ligadas al comercio al por menor $\mathrm{o}$ al artesano, llegando incluso casi a monopolizar determinadas actividades como, por ejemplo, la fabricación del pan, labor esta, por cierto, muy vinculada a los franceses en toda Galicia ${ }^{42}$.

Es innegable la importancia jugada por los grandes comerciantes franceses en el Ferrol del siglo XVIII. A las dificultades inherentes a todo centro urbano del Antiguo Régimen a la hora de asegurarse el abasteci-

${ }^{41}$ En el recuento de trabajadores de la Contaduría Principal de Marina del departamento de 1760 aparece con el grado de ingeniero segundo y un sueldo de 1.370 reales. VIGO, A., Opus cit., Vigo 1985, p. 139-142.

${ }^{42}$ REY, O., «Movimientos migratorios en Galicia, siglos XVI-XIX», pp. 27-72, en, EIRAS, A. y Rey, O. (Eds.), I Conferencia Europea de la Comisión internacional de demografia histórica, Santiago 1993, (2 vols.), Vol. 1, p. 46. 
miento de los productos de primera necesidad -y de entre ellos fundamentalmente el pan-como elemento capital para afianzar la calma social, Ferrol unía sus peculiaridades geográficas, la pobreza agrícola de su comarca -incapaz de abastecer un centro urbano de las dimensiones del departamental- y las nefastas comunicaciones terrestres, lo que la convertían en una localidad muy necesitada del comercio marítimo externo para su correcto abastecimiento $y$, por ende, constituía un centro urbano mucho más expuesto a una crisis de subsistencias que el resto de localidades del reino. Además, la importancia estratégica del enclave empeoraba aún más si cabe la situación, al ser objeto en momentos de guerra de estrechos bloqueos navales que impedían la llegada de los necesarios acopios de cereal, provocando importantes subidas en los precios e incluso el certero peligro de una situación insostenible. Por si fuera poco, la pobreza de las tierras del entorno motivaba que los campesinos de los alrededores también se dirigieran a la ciudad con el fin de contrarrestar su déficit de cereal con la compra de éste en el mercado departamental.

Buena parte de esas relaciones comerciales vinculadas con la materia prima para la fabricación del pan van a ser monopolizadas por los grandes comerciantes franceses asentados en la localidad gallega ${ }^{43}$, unos comerciantes que con frecuencia fletarán embarcaciones para atraer hacia Ferrol el tan preciado alimento, surtiéndose fundamentalmente del trigo francés, embarcado en el puerto galo de Bayona, al menos hasta el enfriamiento de relaciones entra España y Francia, que los llevará a intensificar las importaciones desde las excolonias británicas de Norteamérica -en especial Filadelfia- así como desde la meseta castellana a través de los puertos cántabros. Los comerciantes franceses ${ }^{44}$, sabedores de los proble-

${ }^{43}$ Ello no es óbice para que existan también comerciantes españoles en el sector, como Miguel Regueras, D. José Gasso, Juan Bautista Pol, Tomás Meléndez, Félix Grau o D. Jacobo de la Fuente, o incluso de otras nacionalidades como el británico ya citado Luis Meagher O’Brien, que entre otros negocios también se dedicará a la importación de grano o harina a la ciudad.

${ }^{44}$ Nombres como Juan Dufós, Michel Douband, Juan Lestache, D. Pedro Michel, Juan Lembeie o Dugarder introdujeron importantes remesas de trigo y maíz en el Ferrol de 1769 , en un momento de especial escasez de estos frutos en la localidad. A.M.F., Libros de actas, $\mathrm{n}^{\circ} 8$, fols. 152-152 vto. y 180-192 vto. De manera similar actuará Santiago Beaujardin en marzo de 1788 , momento de nuevo de escasez en la capital departamental, por lo que pedirá licencia al Consejo de Castilla para extraer de 8 a 12.000 fanegas de trigo de la meseta castellana. A.M.F., Libro de actas, $\mathrm{n}^{\circ} 16$, fol. 18. 
mas de abastecimiento que asolaban la ciudad, depositaban en sus almacenes los barriles de harina y esperaban el momento más propicio para sacarlos al mercado, exprimiendo los mejores rendimientos posibles ${ }^{45}$. Asimismo, algunos de ellos invirtieron grandes sumas de capital en la construcción en la comarca ferrolana de importantes infraestructuras de transformación del cereal que abarataran los costos de desplazamiento y posibilitaran un enriquecimiento mayor y un marco geográfico de acción más amplio. Sin duda el ejemplo más conocido es el de los molinos levantados en Jubia por Juan Lestache y su socio Francisco Bucan, calificados por Larruga como "una construcción ventajosa»" ${ }^{46}$. Se molían en sus cuatro ruedas de piedra pedernal de Francia unas 70.000 fanegas de trigo anuales, la mitad de harina flor y la otra mitad de segunda calidad y buena parte de esa producción era enviada a América y a otros lugares de la geografía española, siempre que las necesidades de Ferrol no obligasen a su requisa por parte de las autoridades locales. Se surtía la fábrica de cereales de Galicia, Castilla, Holanda, Rusia, Francia y Filadelfia ${ }^{47}$.

Pero si el comercio del trigo era un elemento capital en las inversiones francesas en Ferrol, sin duda la localidad presentaba también otras posibilidades como, por ejemplo, los asientos de la Corona para los arsenales,

\footnotetext{
${ }^{45} \mathrm{~A}$ este respecto son muchas las disposiciones del concejo ferrolano para obligar a todos los comerciantes de grano al por mayor a abrir sus depósitos y vender sus mercancías a un precio justo.

${ }^{46}$ LARRUGA, E., Memorias políticas y económicas sobre los frutos, comercio, fábricas y minas de España, Vol. 15, Zaragoza 1995-1996 (1 ${ }^{\text {a }}$ Ed. Madrid 1787-1797), p. 130.

${ }^{47}$ A.M.F., Estadística sobre industrias, Carp. 473. Sin duda, los molinos de Jubia se convirtieron en el estandarte de las actividades económicas desarrolladas por los franceses en la comarca ferrolana, aunque hubo otros intentos por parte de comerciantes galos para crear instalaciones similares. Por ejemplo, el 4 de marzo de 1801, Juan Segofin, panadero y vecino de la villa de Ferrol, solicitaba al Consejo de Castilla permiso para cerrar 20 varas de mar en A Malata con el fin de construir unos molinos harineros "cuio tan preciso requisito es mui necesario en toda esta comarca para de esta suerte no carecer de pan en todos tiempos la enunciada casería, como los más naturales (aún caso que acaezca entrar en dicho puerto el enemigo) cuia tan piadosa obra es mui urgente, y no tan solamente esto, sino la de obligarse por si propio y a su riesgo mandar concurrir de dibersas partes partidas crecidas de trigos, a efecto de con mexor comodidad abastecer con más abundancia a la mencionada cesería y juntamente a los vezinos(...) cuia obra después de fabricada será una ermosura el verla». Todo quedará, sin embargo, en un mero proyecto. A.H.N., Consejos, Leg. 2031.
}

«CUADERNOS DE ESTUDIOS GALLEGOS», Tomo XLVIII, Fascículo 114, Santiago 2001. 
con los cuales se podía conseguir el monopolio ya sobre productos de primera necesidad, ya sobre materiales indispensables para la construcción naval. Ese era el caso de Juan Obertin, que compaginaba en 1759 su labor como maestro herrero en la maestranza ferrolana con la de asentista "en la obra de su oficio ${ }^{48}$, algo que sería a todas luces incompatible en nuestros días. Asimismo, los franceses aparecen a lo largo de la segunda mitad de la centuria desempeñando la representación comercial de diferentes países, por ejemplo, en el padrón de 1765 encontramos a dos ejerciendo ese papel: Pedro Villanueva, apoderado de la nación holandesa y Juan Lamaigniere, representante de la francesa, puesto éste que ocupará a finales de la centuria Santiago Beaujardin.

El grupo de franceses trabajando en actividades artesanales o de venta al por menor era cuantitativamente hablando el más importante ${ }^{49}$, suponía en 1778 -año cumbre de la presencia gala en la localidad gallega- el $43^{\prime} 4 \%$ del total de asentados en la villa ${ }^{50}$. De entre todos los oficios eran los relacionados con el calzado -maestros zapateros, oficiales, maestros de obra prima, etc.- los que aglutinaban un mayor número de inmigrantes ${ }^{51}$. Les seguían aquellos vinculados a la fabricación del pan, labor como ya dijimos muy relacionada con los franceses en la época. Sin embargo, esta relación con la fabricación del pan no implicaba en la mayoría de los casos una posición superior en la pirámide laboral del sector. Había un número destacado de franceses trabajando en los hornos ferrolanos, pero pocos de ellos poseían sus propias instalaciones, el resto eran horneros, aprendices o panaderos asalariados en hornos ajenos, tanto de españoles como de compatriotas ${ }^{52}$. Más atrás aparecen otras labores como la de la

\footnotetext{
${ }^{48}$ A.G.M., Sección Ferrol, Leg. 100.

${ }^{49}$ En el padrón de 1778 estos empleos suponen el 52'1\% del total y en el de 1791 el $61^{\prime} 3 \%$.

${ }^{50}$ De los 106 franceses registrados, 46 desempeñaban estos oficios.

${ }^{51}$ En el padrón de extranjeros de 1778 aparecen 18 franceses trabajando en el sector.

${ }^{52}$ En el recuento de 1778 aparecían un total de 11 franceses trabajando en la elaboración del pan, los mismos que en 1791, sin embargo el número de propietarios de horno era mucho menor. El 8 de enero de 1790 el ayuntamiento ferrolano repartía entre todos los panaderos de la Real Villa 8.000 ferrados de trigo procedente de A Coruña. De los 9 fabricantes de pan indicados en el repartimiento, 2 (Juan Lavat y Francisco Estripot) eran franceses y ocupaban un lugar preeminente en cuanto a las cantidades de trigo recibidas, siendo tan sólo superados por Juan de Sanmartín que adquiría 3.000 ferrados frente a los 1.700 de Lavat y 800 de Estripot. A.M.F., Libros de actas, $\mathrm{n}^{\circ} 18$, fol. 3.
} 
confección -maestros sastres, oficiales y aprendices-, el pequeño comercio, sobre todo de quincalla, o la regencia de una taberna o un billar. Había, asimismo, algunos oficios de una consideración mayor, aunque eran casos muy puntuales, por ejemplo el librero y encuadernador normando Luis Lainé, o el relojero Pedro Valier, natural de Lyon.

Otro de los sectores en donde desarrollaban sus actividades los franceses era en el «público», sin duda el principal motor del desarrollo económico y demográfico de la localidad. Dejando a un lado los casos un tanto excepcionales de Gautier o de La Croix, en este sector los franceses se distribuían en dos grupos: aquellos que desarrollaban sus actividades como miembros de la maestranza, y aquellos otros que estaban vinculados a la carrera de las armas, ya sea como oficiales, ya sea como simples soldados. En lo que respecta a los trabajadores de la maestranza, su número era muy pequeño en comparación al volumen humano encuadrado en los trabajos del arsenal y los astilleros. Por poner un ejemplo, en el recuento de 1778 de los 106 franceses registrados, 38 trabajaban para el rey, seis años más tarde el número de trabajadores de la maestranza ferrolana era de 3.343 hombres $^{53}$, es decir, los franceses constituían un exiguo 1'1\% del total de operarios. Casi la mitad de ellos se encontraban trabajando como herreros en las instalaciones militares y procedían casi exclusivamente de la provincia de Bearne. Junto a ellos encontramos también carpinteros de ribera, calafates, carpinteros de blanco o faroleros, con una distribución geográfica más dispersa. Asimismo habría que subrayar dentro de este grupo a algunos individuos con un estatus mayor en el panorama laboral con respecto a sus compatriotas, por un lado Francisco Belloq que desempeñaba el cargo de escultor en los astilleros de Esteiro y por otra Juan Marland que era maestro de lenguas en la academia de guardias marinas.

En cuanto a los franceses sirviendo al rey como militares, desgraciadamente quedan fuera de los padrones de extranjeros confeccionados por el concejo ferrolano. Sin embargo tenemos noticias indirectas que nos hablan de su presencia en este campo profesional; por ejemplo, la destacada participación,gala en los regimientos de extranjeros que sirvieron de guarnición para la real villa e incluso de mano de obra barata en los traba-

${ }^{53}$ B.M.N., Estado General de la Armada, Madrid 1785. 
jos de las reales obras. En los listados de tropa de regimientos como el de Ibernia, Milán, Bruselas, Irlanda o incluso de los batallones de marina, aparecen abundante número de apellidos franceses que delatan esa relación. Algunos de estos militares de tropa decidirán una vez cumplidas sus obligaciones con el rey asentarse en la capital departamental, a veces empleándose en las reales obras merced a un oficio aprendido en su periplo castrense y otras abriendo una tienda o una taberna, si no la tenían ya abierta antes de su licenciamiento. A este respecto el padrón de extranjeros de 1791, sin duda el más rico en información de todos, indica que 12 de los 96 franceses registrados en Ferrol en aquellas fechas habían llegado a la localidad sirviendo en algunos de esos regimientos o en la Armada Real ${ }^{54}$.

De la oficialidad francesa al servicio de la Corona española, los datos que poseemos son todavía más escuetos. Sabemos que tras la revolución en el país vecino miembros de la marina gala entraron a servir en la Armada Real y algunos de ellos se encontraban destinados en la base gallega cuando las tropas francesas la sitiaron a comienzos de 1809. Por ese motivo, la Junta de Defensa ferrolana en una de las peticiones de su capitulación ante el mariscal Soult, solicitaban que no se tomase contra ellos ninguna represalia por parte de las tropas invasoras ${ }^{55}$. De la misma manera que a Ferrol llegaron militares franceses huyendo del furor revolucionario, también arribaron a la real villa diez clérigos -nueve seculares y un capuchino $^{56}$ - huyendo de la nueva situación establecida en Francia. El

\footnotetext{
${ }^{54}$ A.M.F., Padrones de extranjeros, Carp. 1016.

${ }^{55}$ «También existen en ella dos o tres oficiales franceses al servicio de la marina real de España, y uno de la real hacienda de la misma marina, que manifestaron no poder tomar las armas contra la Francia, por estar comprometidos al efecto, y se respetó su promesa en términos de que no han hecho, ni se han expuesto a hacer la menor hostilidad». MONTERO, J., Historia y descripción de El Ferrol, Pontedeume 1972 (1ª Ed. Madrid 1859), p. 94.

${ }^{56}$ La lista de sacerdotes es la siguiente: D. Pedro Onore, D. Francisco Covilland -canónigo de Nantes-, D. Santiago Lefevre-cura rector de Soleme-, D. Francisco Simón -cura rector de Dol (Bretaña)-, D. Juan Vicente Marié -Sacerdote de París-, D. Agustín Sorre-vicario de Doel-, D. Francisco Xaquet -cura rector de Alier (Limoges)-, D. Francisco Bullat - vicario y racionero de Limoges-, D. Pedro Belloc - cura de Ygoldt (Navarra francesa)-, D. José Babi -catedrático de filosofía en Augh-y Fray Mateo de Bañeras -capuchino en Granada (Aire)-. A.M.F., Expulsión e embargo dos bens ós franceses, Carp. 1018.
} 
origen de este desplazamiento humano vino dado por la aprobación en la Asamblea Nacional francesa el 12 de julio de 1790 de la Constitución Civil del Clero, sancionada el 24 de agosto del mismo año por Luis XVI sin esperar la ratificación de Roma. La nueva situación se completó con el decreto del 27 de septiembre por el que la Asamblea obligaba al clero francés a prestar juramento de fidelidad a la nación, a la ley y al rey, así como al nuevo documento. A partir de ese momento comenzará un proceso de fragmentación en el seno de la Iglesia francesa entre juramentados y refractarios que llevará a los segundos, sobre todo tras la caída del poder real, a una insostenible situación de persecución que en muchos casos significará su salida del país ${ }^{57}$. En el caso que nos ocupa, apenas sabemos nada más de ellos que su número y procedencia, si bien al no mencionárseles en las capitulaciones de 1809 no parece descabellado pensar que ya no se encontrarían en la localidad por aquellas fechas, la explicación más coherente puede ser el retorno a su tierra una vez normalizadas las relaciones entre París y Roma en 1799.

A pesar de que el padrón de 1778 es que el que registra un mayor número de franceses residiendo en Ferrol, los datos sobre el lugar de origen de los inmigrantes son poco aprovechables, al mezclar el escribano sin ningún tipo de rubor obispados con provincias, o incluso con simples lugares, lo que hace muy difícil realizar un estudio medianamente coherente. Por el contrario, el recuento de 1791 es mucho más aceptable, al emplear sistemáticamente la región francesa de procedencia. Según este padrón parece evidente que es la Francia suroccidental la que suministra un mayor número de inmigrantes; concretamente las regiones de Gascuña, Bearne y el Languedoc aportan más de la mitad de los franceses residentes en la localidad ${ }^{58}$, quedando otras regiones de fuerte tradición migratoria, como es el caso de Auvernia, en un discreto segundo plano ${ }^{59}$. De la prime-

${ }^{57}$ DE JUANA, J., «Clérigos franceses emigrados a Galicia durante la Revolución Francesa», pp. 7-56, en, DE JUANA, J. y CASTRO, X. (Dirs.), VIII Xornadas de Historia de Galicia, Ourense 1995, p. 9. Para una mayor información sobre este proceso en el ámbito gallego se puede consultar junto al referido artículo de Jesús de Juana el libro de $\mathrm{M}^{\mathrm{a}}$. Luisa Meijide Pardo. Ver, MEIJIDE, M.L., Sacerdotes franceses emigrados durante la revolución a Galicia, Sada 1991.

${ }^{58}$ De los 96 franceses registrados ese año 53 proceden de una de estas tres regiones.

${ }^{59}$ Ver, REY, O., «Gallegos y franceses en un espacio común», pp. 171-194, en, Obradoiro de Historia Moderna, $\mathrm{n}^{\circ}$ 7, Santiago 1998.

«CUADERNOS DE ESTUDIOS GALLEGOS», Tomo XLVIII, Fascículo 114, Santiago 2001. 
ra habría que destacar a la ciudad de Bayona como principal centro suministrador de hombres para Ferrol, una localidad, como dijimos ya, muy relacionada con la capital departamental, al proceder de allí buena parte del trigo consumido en ella a lo largo del siglo XVIII. Es pues constatable el contacto entre los centros urbanos y, por ello, comprensible ese aporte. En cuanto a la contribución humana de Bearne es muy significativa; circunscribiéndose prácticamente a un par de localidades: Pau y Olorón, que aportan mayoritariamente herreros a las Reales Obras. Esta concentración en unos pocos centros poblacionales de un número importante de inmigrantes con una dedicación laboral similar parece remitirnos o bien a una contratación en bloque por parte de la Corona, como había sucedido con los británicos, o bien a un típico ejemplo de cadena migratoria. Nosotros nos inclinamos más por la primera opción, ya que desde el primer padrón de 1765 ya aparecen todos ellos asentados en la villa, además de coincidir en prácticamente todos los casos su paso previo por los astilleros santanderinos de Guarnizo. En cuanto al aporte del Languedoc, prácticamente se concentra en el entorno de Tolosa y en las tierras más próximas a la cadena pirenaica. Precisamente, haciendo un estudio de las procedencias no por regiones sino por departamentos, observamos como el principal foco emisor se reduciría territorialmente a los Bajos y Altos Pirineos, Gers y el Alto Garona ${ }^{60}$.

El padrón de 1791 presenta además otro tipo de información de gran interés, ya que en él las autoridades preguntan el tiempo de estancia tanto en España en general como en Ferrol en particular. En algunos casos, el inmigrante no sólo contesta eso, sino que incluso indica en qué otras localidades había residido antes que en Ferrol, desgraciadamente esta información aparece solamente en 42 de los 96 franceses registrados, aún así nos servirá para trazar aunque sea someramente los comportamientos de este movimiento migratorio. Lo primero a destacar es la importancia jugada en este proceso por el carácter militar de la población de acogida; efectivamente, en 12 casos es evidente que las razones del asentamiento se deben al destino por parte de las autoridades militares en la plaza gallega. Hay 5 franceses que llegan a Ferrol merced a su puesto en la Armada

${ }^{60}$ NORDMAN, D. y OZOUF-MARIGUIER, M., Atlas de la Révolution française, París 1989.

«CUADERNOS DE ESTUDIOS GALLEGOS», Tomo XLVIII, Fascículo 114, Santiago 2001. 
Real y 7 que lo hacen formando parte de los regimientos de extranjeros que protegían la capital departamental. Asimismo, de los 42 casos hay 9 en los que se indica que la última plataforma del proceso migratorio escalonado hacia Ferrol eran las provincias vascas, destacando especialmente la ciudad de San Sebastián. Tal información encaja perfectamente con las características del movimiento humano francés, concentrado precisamente en los territorios limítrofes a aquellas provincias, con quien tenían en común -en el caso de los procedentes del País Vasco francés o de la Navarra francesa- unas costumbres e incluso una lengua. Otra vía de llegada a Ferrol con 5 casos es Cádiz, otra de las sedes de los arsenales de la Corona, con unas relaciones militares e incluso humanas ciertamente intensas durante el siglo XVIII. Por último habría que destacar también Guarnizo con los mismos casos localizados y que corresponden a una parte de los herreros de Bearne que antes de llegar a Ferrol ocupan un puesto en la maestranza santanderina durante un breve período de tiempo.

El comienzo del declive de la presencia francesa en Ferrol vino de la mano de la tensa situación internacional vivida por Europa a finales del siglo XVIII. Las insostenibles relaciones entre la Corona española y la Francia revolucionaria tras la ejecución de Luis XVI se manifestaron en los territorios de la monarquía católica en una dura persecución de todo lo francés, actitud que no se debe entender solamente como una mera represalia de tiempos de guerra, sino también como un auténtico pánico a la posible extensión del proceso revolucionario del país vecino al propio reino, elemento este ya perceptible desde sus mismos albores. De esta manera, el Consejo de Castilla ordenó el 5 de marzo de 1793 «extrañar de los dominios de España a todos los franceses que no se hallen domiciliados en sus respectivos pueblos con oficios $u$ ocupaciones $\rangle^{61}$. En el caso ferrolano, el encargado de hacer cumplir las directrices del Consejo fue su alcalde mayor D. Antonio Francisco Freire que manifestará a lo largo del proceso un sospechoso exceso de celo para con miembros destacados de la colectividad francesa en la Real Villa. Existen casos especialmente sangrantes como el del tendero Lorenzo Estripot, hijo de un panadero francés del mismo nombre que lo había traído a Ferrol desde muy niño en donde se crió, sirviendo incluso al rey en su adolescencia como paje en

${ }^{61}$ A.M.F., Expulsión e embargo dos bens ós franceses, Carp. 1018. 
un navío de guerra y en donde formó una familia. A pesar de las súplicas del francés y de sus razonables alegaciones, el alcalde mayor lo expulsará sin contemplaciones de la localidad embargándole asimismo todos sus bienes, desde la tienda con todos sus productos hasta una casa que poseía en la barrio de Esteiro. Del mismo modo se actúa con dos de los más destacados miembros de la colectividad francesa en la capital departamental: D. Santiago Beaujardin y D. Juan Lembeye. Ambos poseían a medias los famosos molinos y almacenes de Jubia, valorados en más de 400.000 reales, así como otros bienes y negocios que los convertían en hombres con un capital económico más que considerable. Freire actuará con ellos de manera implacable, expulsándolos de la localidad y embargándoles los molinos, a pesar de las airadas protestas de ambos y de estar tramitando un recurso de amparo ante el propio Consejo de Castilla. Tampoco en este caso las razones esgrimidas por los afectados fueron atendidas por el magistrado ${ }^{62}$. Sin embargo, el tiempo demostrará que las medidas de Freire estuvieron fuera de lugar y en los tres casos el Consejo de Castilla dará la razón a los expulsados. Aún así, las medidas tomadas contra esta colectividad dejarán su huella: si en 1791 residían en Ferrol 96 franceses, en abril de 1793 tan sólo quedaban 51, el resto se habían tenido que marchar, a excepción de 7 operarios de la maestranza apartados momentáneamente de la localidad, posiblemente por la poca confianza que inspiraban a las autoridades de marina. Prácticamente todos los que quedaron superaban los veinte años de estancia en España y una abrumadora mayoría de ellos habían formado una familia casándose con una española.

\footnotetext{
${ }^{62}$ Santiago Beaujardin alegaba estar casado con española, perteneciéndole en la partija de sus suegros 170.000 reales de vellón, poseer junto a Lembeye los tan beneficiosos para la ciudad molinos de Jubia y aunque reconocía el no haber jurado fidelidad al rey de España ello se debía a que era teniente cónsul de Francia, mas «se sujetó a berificarlo siempre que S.M. se sirbiese determinarlo». Por su parte, Lembeye afirmaba llevar 30 años en la localidad y estar casado con española, haber sido director nato de la Compañía Marítima - de la que poseía 50 acciones de 1000 reales de vellón- "con facultad de concurrir a la corte principalmente a las Juntas Generales que celebra la misma compañía para su mejor govierno" y que no había jurado fidelidad al monarca porque pensaba que ya estaba naturalizado al detentar tal cargo. A.M.F., Expulsión e embargo dos bens ós franceses, Carp. 1018.
} 


\section{ITALIANOS, PORTUGUESES Y OTRAS COLECTIVIDADES EXTRANJERAS EN FERROL}

La colectividad italiana era la segunda en importancia en el contexto general extranjero, tan sólo en el padrón de 1767 cede esa posición a la británica. La presencia transalpina en Ferrol alcanza su mayor expresión a finales de siglo, llegando a suponer el $25 \%$ del total de la colonia extranjera. Los italianos que vienen a trabajar a Ferrol proceden mayoritariamente de las regiones norteñas; así, en el recuento de 1791 de los 48 registrados 33 procedían de Génova, Milán, el Piamonte y Venecia ${ }^{63}$. Asimismo, el principal motor que les empujó a instalarse en la localidad gallega fue el servicio a la Corona, al menos eso indican las referencias que el padrón de 1791 nos ofrece: de los 18 registros útiles, 10 nos hablan de la llegada a la plaza como miembros de diferentes regimientos, tanto de extranjeros -Regimientos de Milán, Bruselas o Ibernia-, como regulares -Regimiento de Navarra o Batallones de Marina-. Asimismo aparecen 2 individuos que arribaron a la ría departamental como miembros de la marinería de la Real Armada. Parece pues la vía militar el principal canal de alimentación de esta colectividad. En cuanto a su dedicación profesional prima la diversificación, si bien parece que son el comercio al por menor con tienda abierta, sobre todo de quincallería, y la venta ambulante las actividades preferentes -10 de los 48 casos-. También aparecen profesiones, concretamente 6 , ligadas a las labores en las instalaciones reales aunque no encontramos, como habíamos observado en el caso francés, una ocupación específica en el sector, sino que más bien se trata de soldados licenciados de los Batallones que realizan actividades muy diversas en el esquema laboral castrense -rondines, miembros de la maestranza, capataces de presidiarios...-. El único ejemplo reconocible de proceso migratorio en cadena en el caso italiano es el de la familia genovesa de los Garibaldo que monopolizaron la fabricación de pasta durante buena parte del siglo tanto para los regimientos que guarnecían la plaza como para los propios habitantes de ella. En 1778 sólo se encontraban residiendo en la villa Antonio y Félix María, trece años después hay seis fideleros todos de esa familia, aunque algunos como Sebastián Garibaldo, mantenían el estatus de transeúnte e incluso se disponían

${ }^{63}$ Aparecen 13 genoveses, 12 milaneses, 5 piamonteses y 3 venecianos. 
por aquellas fechas a retornar a su lugar de origen. Otro caso especialmente singular es el de Nicolás Setaro, empresario de óperas que residía en Ferrol a comienzos de la década de los setenta y que desarrolló su labor no sólo en la capital departamental, sino también en otros centros urbanos del reino de Galicia, como por ejemplo A Coruña.

En lo que respecta a la presencia portuguesa en Ferrol, ésta se circunscribe al último tercio del siglo XVIII, llegando a alcanzar en 1791 el 12'6\% del total de extranjeros. Es evidente que existe para los recuentos de la década de los sesenta cierto grado de ocultación, como de hecho pasaría con los italianos, ya que los padrones no reflejan a aquellos que gozaban de fuero militar, y está perfectamente constatada la presencia lusa en los regimientos de extranjeros e incluso en los batallones de marina de la sede departamental. Más de la mitad de estos portugueses que aparecen reflejados en el padrón de 1791 proceden del norte del reino, destacando el entorno de Braga y entre las actividades desarrolladas por esta colectividad habría que destacar tres; por un lado la fabricación de sombreros, por otro la elaboración de calzado y, por último, la realización de objetos de orfebrería.

El resto de colectividades tenían en la práctica una presencia meramente testimonial; la gran mayoría de los inmigrantes de Centro Europa eran licenciados de los regimientos asentados en la plaza a lo largo del período y se ocupaban en oficios de baja cualificación. Tan sólo los bohemios desempeñaron labores de entidad en el campo económico como comerciantes al por mayor o representantes de compañías con sede en otras localidades, A Coruña fundamentalmente ${ }^{64}$.

\section{CONSIDERACIONES FINALES}

La presencia extranjera en Ferrol durante el siglo XVIII carece de relevancia cuantitativamente hablando si la comparamos con las dimensiones globales del movimiento migratorio hacia la localidad. Sin embargo, la singularidad de algunos de sus casos y la importante relevancia jugada por parte de sus miembros en la esfera económica de la plaza hacía de especial interés su estudio. De entre todas las colectividades, la

\footnotetext{
${ }^{64}$ Trausqui y compañía, Compañía de Juan Adan Sachserquitel.
} 
francesa la que destacaba en cuanto a aporte, desempeñando además un importante papel en ciertas actividades comerciales relacionadas con la introducción en la villa de los tan necesarios acopios de cereales. La zona emisora se situaba, en este caso, en el sudoeste del país vecino, destacando sobre todo el País Vasco y la Navarra francesa.

La colonia británica no fue en ningún momento importante numéricamente hablando pero suscita un especial interés al representar un caso un tanto singular en el panorama migratorio ferrolano por ser un claro ejemplo de migración bajo contrata auspiciada por la Corona en el contexto de la política de recuperación naval abanderada por el marqués de la Ensenada. Por lo que respecta a los italianos y portugueses, los primeros procedían mayoritariamente del norte de la Península Itálica y llegaron a Ferrol como integrantes bien de los regimientos de tierra, bien de la Real Armada. Los lusos por su parte procedían en su mayoría del norte de su país, destacando el entorno de ciudad de Braga. Las demás colectividades poseían una representación meramente testimonial, siendo la carrera de armas la principal vía de llegada. 